Kuala Lumpur, Malaysia. Available at: http://ietec.apaqa.org/wp-content/uploads/IETEC-2011-Proceedings/ papers/Conference\%20Papers\%20Refereed/Wendesday/WP4/WP4.4 59.pdf

[15] WordNet Search - 3.1. Available at: http://wordnetweb.princeton.edu/perl/webwn

[16] Leontyeva, N. N. (2002). K teorii avtomaticheskogo ponimaniya teksta. Chast 3. Semanticheskiy komponent. Lokalniy semanticheskiy analiz. Moscow: Izdatelstvo Moskovskogo universiteta, 49.

[17] Foltz, P. W., Gilliam, S., Kendall, S. (2000). Supporting Content-Based Feedback in OnLine Writing Evaluation with LSA. Interactive Learning Environments, 8 (2), 111-127. doi: 10.1076/10494820(200008)8:2;1-b;ft111

[18] Landauer, T. K., Laham, D., Rehder, B., Schreiner, M. E.; Shafto, M. G., Langley, P. (Eds.) (1997). How Well Can Passage Meaning be Derived without Using Word Order? A Comparison of Latent Semantic Analysis and Humans. Proceedings of the 19th Annual Meeting of the Cognitive Science Society, 412-417. Available at: http://lsa.colorado.edu/papers/cogsci97.pdf

[19] Gryshanova, I. Yu. (2016). Analitychniy oglyad metodiv ta zasobiv semsntichnoho poshuku v semantic web. Problems of programming, 1, 51-72.

[20] Uspenskii, I. V. Internet-marketing. Metody poiska informatsii. Biblioteka «Polka bukinista». Available at: http://polbu.ru/uspensky_inetmarketing/ch45_i.html

[21] Shelmanov, A. O. (2015). Issledovanie metodov avtomaticheskogo analiza tekstov i razrabotka integrirovannoy sistemy semantiko-sintaksicheskogo analiza. Moscow, 210. Available at: http://www.ipiran. ru/announce/dissertation_Shelmanov.pdf

\title{
APPLICATION OF FUZZY MATHEMATICS METHODS TO PROCESSING GEOMETRIC PARAMETERS OF DEGRADATION OF BUILDING STRUCTURES
}

\author{
Svitlana Terenchuk \\ Department of Architectural Structures \\ Kyiv National University of Civil Engineering and Architecture \\ 31 Povitroflotskiy ave., Kyiv, Ukraine, 03680 \\ terenchuksa@ukr.net \\ Bohdan Yeremenko \\ Department of information technology of design and applied mathematics \\ Kyiv National University of Civil Engineering and Architecture \\ 31 Povitroflotskiy ave., Kyiv, Ukraine, 03680 \\ erembm@ukr.net \\ Serhii Kartavykh \\ Department of information technology of design and applied mathematics \\ Kyiv National University of Civil Engineering and Architecture \\ 31 Povitroflotskiy ave., Kyiv, Ukraine, 03680 \\ snk07@ukr.net \\ Oleksandr Nasikovskyi \\ Development Investment Management \\ Limited Liability Company \\ 8 baisy Okipnoy str., Kyiv, Ukraine, 02002 \\ avnukraina@gmail.com
}

Abstract

The aim of research is formalization of the expert experience, which is used in processing geometric parameters of building structure degradation, using fuzzy mathematics. Materials that are used to specify fuzzy models are contained in expert assessments and scientific and technical reports on the technical condition of buildings. The information contained in the reports and assessments 
is presented in text form and is accompanied by a large number of photographs and diagrams. Model specification methods, based on the analysis of such information on the technical state of structures with damages and defects of various types, primarily lead to difficulties associated with the presentation of knowledge and require the formalization of expert knowledge and experience in the form of fuzzy rules. Approbation and adaptation of the rules is carried out in the process of further research taking into account the influence of random loads and fields. The scientific novelty of the work is expanding of the knowledge base due to the geometric parameters of structural degradation, on the basis of which a fuzzy conclusion about their technical state in the systems of fuzzy product rules at different stages of the object's life cycle is realized. The results of the work are presented in the form of a formalized description of the geometric parameters of degradation. The knowledge presented in the work is intended for the development of technical documentation that is used at the pre-project stage of building reconstruction, but the gained experience is the source of information on the basis of which a constructive solution is selected in the design process of analogical objects. In addition, the knowledge gained from the analysis of expert assessments of the state of various designs is necessary for development of automated expert evaluation processing systems. The use of such evaluation systems will significantly reduce the risks of the human factor associated with the errors in the specification of models for predicting the processes of structural failure at various stages of ensuring the reliability and safety of buildings.

Keywords: knowledge base, building structure, technical condition, expert assessment system. Serhii Kartavykh, Oleksandr Nasikovskyi

\section{Introduction}

Calculation of structures for progressive destruction is one of the requirements for design and provides for local destruction or destruction of individual elements of load-bearing structures within a single floor or parts of floors that do not lead to the destruction of the structure as a whole. In this case, the development of cracks and plastic deformations in individual structural elements and reinforcement is allowed. The choice of the most likely scenarios of emergency destruction is carried out jointly by the designer and the customer, taking into account the factors reducing the bearing capacity of structures [1].

Planning and implementation of construction, repair work and reconstruction of buildings and structures in dense urban development, has a number of features that characterize poorly structured tasks. This class of tasks acquires a mass character and requires the development and implementation of new methods and tools for their solution that will increase the level of automation of the decision-making process in fuzzy conditions in the early stages of ensuring the reliability and safety of construction projects [2, 3]. Given that the described task is not sufficiently formalized, it is especially relevant in this direction to use expert systems with fuzzy logic.

The main aim of the work is formalization of the expert experience, which is used in the processing of geometric parameters of building structure degradation, using fuzzy mathematics, which will significantly increase the degree of automation of evaluation systems.

To achieve this aim, the following tasks are formulated:

- to formalize the geometric parameters of structural degradation, which are characterized by fuzzy information about the position, shape and size of the area of the figure, covering the area of destruction;

- to expand the existing knowledge base due to the geometric parameters of degradation, on the basis of which an indistinct conclusion is drawn about the technical state of structures in the systems of fuzzy product rules.

\section{Materials and methods of research}

Earlier, the approach based on models and methods of fuzzy mathematics was described in [2-4], and examples of formalizing some geometric parameters of cracks and parameters of the influence of the medium on the kinetics of their development are described [4, 5]. In this paper, the main attention is paid to the processing of information on defects and destruction of load-bearing structures of the building, which are characterized by parameters of the girth area (Fig. 1). 


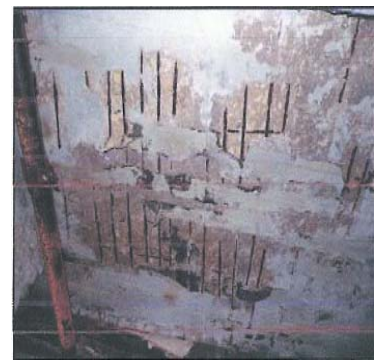

a

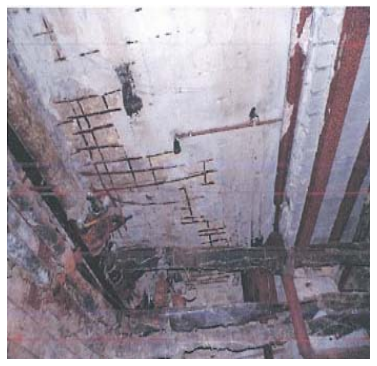

b

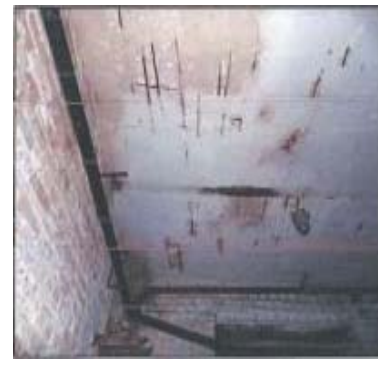

$c$

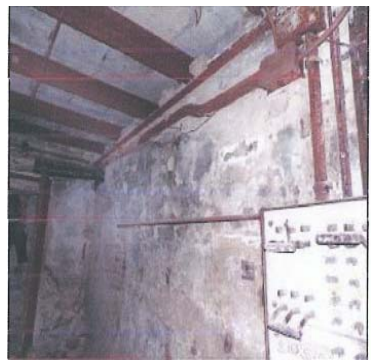

$d$

Fig. 1. Photos - fragments of the basement condition: $a, b, c$-destruction of the protective layer of concrete overlapping of different sizes and area formations on the sections of the ceiling and the abutment of the ceiling to the wall; $d$ - traces of water saturation, bloom and fungus on sections of the wall with an area of $4 \mathrm{~m}^{2}$

Below are examples of the description of the destruction of structures that were discovered during the next visual inspection of the building [6].

Facade in axes 1-6 (links to pictures and photos):

- destruction of the plaster layer, weathering of the mortar from the seams of the wall masonry in the places of the spillway funnels due to the sedimentation by atmospheric precipitation in the areas of $1 \mathrm{~m}^{2}$ and $5 \mathrm{~m}^{2}$ (photos).

Facade in axes $\mathbf{A E}$ (links to figures and photos):

- destruction of the plaster layer, weathering and washing out of the mortar from the seams of the brickwork of the wall under the window openings of the second floor on a plot of $1 \mathrm{~m}^{2}$ (photo).

1st floor (links to layouts and photos):

- destruction of the concrete steps of the march on the sections $1100 \times 150 \mathrm{~mm}, 1700 \times 150 \mathrm{~mm}$, $1800 \times 90 \mathrm{~mm}$ (diagram and photo);

- detachment of the facing layer of concrete in the walls of the staircase at the site of $2500 \times 2600 \mathrm{~mm}$ (diagram and photo).

3rd floor (links to figures and photos):

- traces of water saturation, bloom, destruction of the facing layer of concrete on sections of walls with an area of $0.6 \mathrm{~m}^{2}$ (photo).

4th floor (links to figures and photos):

- traces of water saturation, bloom, on sections of walls with an area of $7.0 \mathrm{~m}^{2}$ (photo).

Basement (links to pictures and photos):

- traces of water saturation, bloom, fungus, destruction of the facing and plaster layer of concrete on sections of walls with a total area of $30.0 \mathrm{~m}^{2}$ (photo).

The following is an extract from a typical assessment of the technical condition and operational fitness of the load-bearing structures of the building, which were used to derive fuzzy estimation rules [6].

Extract. When examining the interior, there were signs of destruction of the plaster layer of concrete in the sections of the basement overlap; destruction of concrete steps of the march of the 1st floor; destruction of the plaster layer in the room of the 4th floor in the axes E-F/1-2; traces of water saturation; bloom; fungus; destruction of the facing and plaster layer of concrete on the sections of the walls of the 1st, 3rd and 4th floors with a total area of $30.0 \mathrm{~m}^{2}$. According to the results of the assessments, it is established that the structure of the building is in a satisfactory condition, with the exception of the monolithic reinforced concrete floor of the basement.

The fuzzy inference system includes [4]:

- set of fuzzy linguistic variables, with the help of which experts describe the type of defects and the state of the structures;

- rules on fuzzy variables;

- inputs and outputs of the system. 
Incoming parameters are specified in the form of a vector which coordinates can be, for example, the geometric parameters of defects and fractures. In this paper, it is proposed to extend the vector of initial data due to the geometric parameters of degradation, which are characterized by fuzzy position, shape and size of the area of the figure encompassing the area of destruction. Each incoming parameter corresponds to a linguistic variable, which, in turn, consists of a certain number of terms. Each term is a fuzzy set (Table 1).

Table 1

Example of formalization of geometric parameters of structural degradation

\begin{tabular}{|c|c|c|}
\hline Type of the defect & Parameter $(\mathbf{i}=\mathbf{1}, \ldots, 8)$ & Terms for linguistic evaluation \\
\hline$Y_{1}-$ crack & & Described in [4] \\
\hline $\begin{array}{l}\mathrm{Y}_{2}-\text { bloom; } \\
\mathrm{Y}_{3} \text { - fungus; }\end{array}$ & $\mathrm{y}_{\mathrm{i} 3}-$ coverage area size & zero (ze); insignificant (ins); essential (es); extensive (ex); \\
\hline $\begin{array}{l}Y_{4}-\text { traces of water saturation; } \\
Y_{5} \text { - peeling off the facing layer of } \\
\text { concrete; }\end{array}$ & $\mathrm{y}_{\mathrm{i} 4}-$ coverage area form & $\begin{array}{l}\text { triangular (t); rectangular (r); trapezoidal (tr); ellipsoid (e); } \\
\text { spherical (sph); sector-like (s); }\end{array}$ \\
\hline $\begin{array}{l}\mathrm{Y}_{6}-\text { destruction of the plaster layer } \\
\text { of concrete; } \\
\mathrm{Y}_{7}-\text { exfoliation of concrete sur- } \\
\text { face; } \\
\mathrm{Y}_{8}-\text { destruction of concrete. }\end{array}$ & $\begin{array}{l}y_{i 7}-\text { defect position in the } \\
\text { object }\end{array}$ & $\begin{array}{l}\text { on the facade (f), in the seams between the slabs (sbp); along the } \\
\text { armature (aa); in the shelves of plates (sp); on overlapping areas } \\
\text { (oa); on sections of walls (w); near supports (in); on sections } \\
\text { of the ceiling (directions); on the steps of the flight (sf); above } \\
\text { window cuts (wc); under the window slots (ws). }\end{array}$ \\
\hline
\end{tabular}

In addition to the descriptions of parameters of structural degradation adopted in the current standards, the specifics of the provision and processing of textual information and software [4, 5], which is used to form a system of fuzzy inference, were taken into account. When choosing the terms for the linguistic evaluation of the geometric parameters of degradation, which are characterized by fuzzy information about the figure encompassing the area of destruction, analysis of photos of destruction a (Fig. 1) and method of associations [7-9] was used.

The output of a rule is a linguistic variable, which in the given subject area represents the category of a technical state and is characterized by a set of terms normal (N); satisfactory (S); not suitable for normal operation (NS); and emergency (E).

The system of fuzzy rules for evaluating the effect of each defect on the state of constructions consists of formalized expressions that have the form $[2,5]$ :

Rule 1: if $<$ defect type - high - area size - minor - triangular shape of the area, and position on overlapping areas $>$ than $<$ state normal $>$;

Rule 2: if <type of defect - traces of water saturation - the size of the area - significant - the shape of the area is ellipsoid, and the position - on the overlapping areas $>$ than $<$ the state is normal $>$;

Rule 3: if $<$ defect type - high - area size - minor - triangular shape of the area, and position in overlapping areas $>$ than $<$ state normal $>$;

Rule 4: if <type of defect - destruction of the plaster layer of concrete - the size of the area significant - the shape of the area is incorrect, and the position is on the wall sections $>$ than $<$ state is satisfactory>.

The rules are formed on the basis of an expert assessment of the technical condition of the bearing structures of the building, which is carried out in accordance with the qualification criteria of the current regulatory documents [6].

The method of fuzzy inference and the formation of a system of fuzzy inference based on the Sugeno model, as well as an example of the use of fuzzy rules for estimating the degree of suitability for the exploitation of spanning bridge spanning structures, are described in detail in [4]. The article [5] formalizes the factors influencing the environment on the rate of destruction of reinforced concrete structures and shows the technology of control of the rules base, by means of which a fuzzy knowledge base is constructed to assess their technical condition. 
Forecasting of possible consequences is determined by a set of detected defects and disruptions, according to another system of rules that determine the degree of reduction in the bearing capacity of structures, taking into account operating conditions and medium factors. Publication of research results in this direction is planned in the following articles.

\section{Computational experiments}

The authors of $[2,3]$ apply the described approach in practice in the development of systems for diagnosing the technical condition of buildings and structures using artificial neural networks, but the training of neural networks presupposes the existence of a reliable knowledge base. Thus, the results of the analysis of scientific and technical reports and evaluations obtained in this article can be used to verify the adequacy of fuzzy models that form a training sample. In addition, fuzzy logic methods are effective when models for estimation are built on small samples, and can be used by experts to improve techniques for assessing the technical state of structures $[3,9]$. The development of both proposed directions is based on an analysis of the results of computational experiments.

The scheme of computational experiments using the expert system for assessing the technical state (SATS) of building structures is shown in Fig. 2.

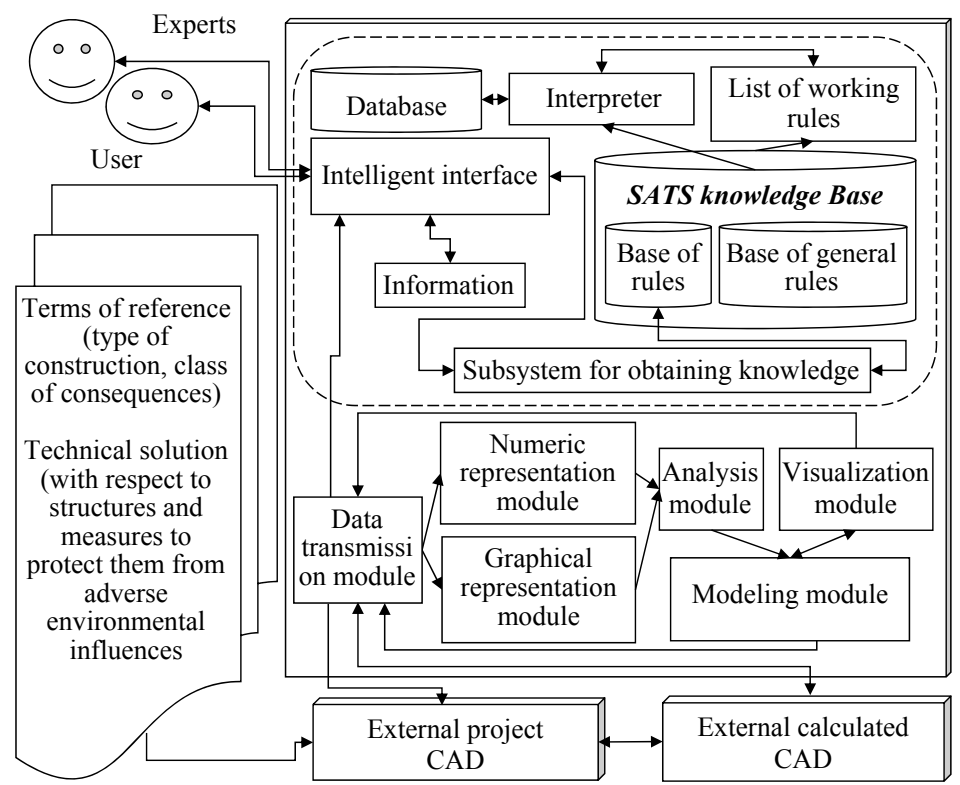

Fig. 2. The scheme of computing experiments

The algorithm for setting parameters and creating a list of working rules by the user, as well as step-by-step expert support for decision making during the diagnostics using MATLAB, is described in [5]. All parameter values and rules that are determined by experts or users are accumulated and stored in the SATS knowledge base, after which the diagnostic results can be used in such computational experiments when choosing constructive solutions at the pre-project stage and the design stage of analogical objects.

In the work, the results of computational experiments were used by experts to predict the technical state of reinforced concrete structures with defects and damages of various types. At the same time, LIRA-CAD computational complexes are used, but experts have the opportunity to choose CAD for diagnostics $[1,5]$.

\section{Results}

SATS knowledge base is part of the system of assessing the technical condition of building structures, which contains a representation of the system on the subject area $[2,3,5]$. The static part of the knowledge base preserves long-term knowledge that describes the subject area in the form 
of general rules and facts. Working memory (database) is a dynamic part of the knowledge base, in which the original and intermediate data are stored $[3,10]$.

Table 3is the database fragment that is used to form the list of working rules by the system of estimating the technical state of building structures is shown (Fig. 2).

Table 3

A formalized description of entities and their attributes

\begin{tabular}{|c|c|c|}
\hline No. of attribute & Name of attribute & Data type \\
\hline \multicolumn{3}{|c|}{ Element (object) } \\
\hline 1 & Object code & Numerical \\
\hline 2 & Object type & Text \\
\hline \multicolumn{3}{|c|}{ Technical conditions } \\
\hline 1 & Category of technical condition & Symbolic \\
\hline 2 & Operation period & Symbolic \\
\hline \multicolumn{3}{|c|}{ Geometrical characteristics of the object } \\
\hline 1 & Marking of the object (code) & Symbolic \\
\hline 2 & Height of the object & Numerical \\
\hline 3 & Width of the object & Numerical \\
\hline 4 & Length of the object & Numerical \\
\hline \multicolumn{3}{|c|}{ Rule of the standard } \\
\hline 1 & Unique rule identifier (code) & Symbolic \\
\hline 2 & The point of rule in the standard & Symbolic \\
\hline 3 & Text description of the rule & Text \\
\hline 4 & Rule formula & Symbolic \\
\hline \multicolumn{3}{|c|}{ Scheduled inspection of the object } \\
\hline 1 & Identification code of the planned survey & Symbolic \\
\hline 2 & Text description of the survey & Text \\
\hline 3 & Date of the survey & Date \\
\hline \multicolumn{3}{|c|}{ Geometrical parameters of the defect during the current survey } \\
\hline 1 & Defect code & Numerical \\
\hline 2 & Name & Symbolic \\
\hline 3 & Fuzzy parameters of degradation & Symbolic \\
\hline 4 & Description of the defect & Text \\
\hline 5 & A photo & Graphical \\
\hline 6 & Position of the defect & Text \\
\hline 7 & Date of establishment & Date \\
\hline 8 & Date of the survey & Date \\
\hline
\end{tabular}

Thus, the research result is the expansion of existing knowledge bases by adding the entity "Geometric parameters of the defect during the current survey" and rules that can be used to assess the technical condition of building structures.

\section{Conclusions}

1. The advantage of using models and methods of fuzzy mathematics in the diagnostics of building structures is increasing the degree of automation of expert systems by formalizing the geometric parameters of degradation, which are characterized by fuzzy shape and size of the area of the figure encompassing the area of destruction. In addition, the need to use information about the position of the defect in the object and the geometric characteristics of the object (structure) is taken into account. However, the use of this approach is significantly hampered by the lack of a single information regulatory framework that could be used to build fuzzy rules.

2. Research materials obtained as a result of the analysis of real assessments of the technical condition of building structures with defects and disruptions of various nature can be used by specialists in the development of software applications for expert systems for assessing the technical 
condition of building structures which work is related to the processing of fuzzy data on the state of structures and modeling degradation processes in fuzzy conditions. In the opinion of the authors, the use of such systems will significantly improve the reliability of forecasting and reduce the risks of the human factor when making constructive decisions in the current conditions of uncertainty and risks of a different nature.

\section{Acknowledgements}

The presented work is the result of an analysis of scientific and technical assessments that were provided for research by a group of companies of the full-cycle developer-building holding company "DIM: group" (Development Investment Management). The authors of the article express their gratitude to the management of the holding for information and financial support of research aimed at the introduction of advanced scientifically grounded information technologies and systems in the design processes.

\section{References}

[1] Chen, G., Ma, Y.-S., Thimm, G., Tang, S.-H. (2004). Unified Feature Modeling Scheme for the Integration of CAD and CAx. Computer-Aided Design and Applications, 1 (1-4), 595-601. doi: 10.1080/ 16864360.2004.10738303

[2] Haina, H. A. (2010). Kontseptsiia bahatomodelnoho pidkhodu do rozrobky intelektualnykh SPPR u mistobuduvanni. Upravlinnia rozvytkom skladnykh system, 1, 28-34.

[3] Terentyev, O., Poltorak, O. (2016). Development of models and methods for determining the physical deterioration of items for the task of diagnostics of technical condition of buildings and structures. ScienceRise, 8 (2 (25)), 14-19. doi: 10.15587/2313-8416.2016.76318

[4] Terenchuk, S. A., Yeremenko, B. M., Pashko, A. O. (2016). Otsiniuvannia tekhnichnoho stanu budivelnykh konstruktsii na osnovi nechitkoho vyvedennia. Budivelne vyrobnytstvo, 61, 23-31.

[5] Terenchuk, S., Yeremenko, B., Sorotuyk, T. (2016). Implementation of intelligent information technology for the assessment of technical condition of building structures in the process of diagnosis. Eastern-European Journal of Enterprise Technologies, 5 (3 (83)), 30-39. doi: 10.15587/1729-4061.2016.80782

[6] Yeremenko, B. M., Terenchuk, S. A., Kartavykh, S. M., Nasikovskyi, O. V. (2017). Zastosuvannia ekspertnykh znan dlia formuvannia bazy znan systemy otsiniuvannia tekhnichnoho stanu budivelnykh konstruktsii. Nauka ta budivnytstvo, 4, 63-69.

[7] Cucakovic, A. (2010). Nacrtna geometrija. Beograd: Akademska misao.

[8] George, A. (2011). Advansed in Biomemetrics. In Tech, Rijeka.

[9] Cook, D. A., Ledbetter, S., Ring, S., Wenzel, F. (2000). Masonry crack damage: its origins, diagnosis, philosophy and a basis for repair. Proceedings of the Institution of Civil Engineers - Structures and Buildings, 140 (1), 39-50. doi: 10.1680/stbu.2000.140.1.39

[10] Larose, D. T. (2005). Discovering Knowledge in Data: An Introducing to Data Mining. Wiley \& Sons, Inc, 240. doi: 10.1002/9781118874059 